\title{
Prevalence of transfusion transmissible infections in blood donors of Pakistan
}

\author{
Aisha Arshad, Munira Borhany ${ }^{*}$, Nida Anwar, Imran Naseer, Rehan Ansari, Samson Boota, Naveena Fatima, \\ Mustansir Zaidi and Tahir Shamsi
}

\begin{abstract}
Background: Transfusion-transmitted infections threaten the safety of patients requiring blood transfusion, which in turn imposes serious challenges for the availability of safe blood products that are still affordable in health care systems with limited resources. The aim of the study was to determine the prevalence of transfusion-transmitted infections in blood donors and to evaluate the demographic characteristics of reactive and non-reactive blood donors.
\end{abstract}

Methods: A prospective cohort study was conducted at our institute in Karachi, Pakistan. Donors were required to fill a detailed questionnaire and were screened for Hepatitis B, Hepatitis C, Human immunodeficiency viruses, Syphilis and Malaria by ELISA and thick film (malaria).

Results: Of the 16,602 blood donors, 16,557 were males and 45 females (mean age 28.6 \pm 2 ). Nine hundred and seventy three (5.8\%) donations were reactive in any screening assay, with $58(0.35 \%)$ donations reacting in more than one assay. The prevalence of Hepatitis B, Hepatitis C, Human immunodeficiency viruses, Syphilis and Malaria was found to be $1.84,1.7,0.04,2.1$ and $0.07 \%$ respectively. Characteristics among the infections were evaluated and it was found that unmarried donors had a higher chance to be infected by Hepatitis B virus and Syphilis as compared to the other infections. On the other hand, construction workers and married donors were at more risk to be infected by Syphilis rather than the other infections. In case of co-infections, personnel with different occupations and marital status were infected by more than one pathogen.

Conclusion: A substantial percentage of the blood donor's harbored transfusion-transmitted infections. Prevention of TTls should be the main goal right now. There is a need for stringent selection of blood donors with the emphasis on getting voluntary donations and comprehensive screening of donor's blood for TTls using standard methods to ensure the safety of blood recipient.

Keywords: Blood bank, Hepatitis, Syphilis, Pakistan

\section{Background}

Blood donation saves the lives of millions of people worldwide; however, the patients are at a potential risk of contracting transfusion-transmitted infections (TTIs), which in turn impose serious challenges to the medical providers for the availability of safe and affordable blood products. According to the World health organization (WHO), safe blood is a universal right. A crucial requirement in the procurement of safe blood is to have a

\footnotetext{
* Correspondence: muniraborhany@gmail.com

Department of Blood Bank of National Institute of Blood Disease and Bone Marrow Transplantation (NIBD), St 2/A block 17 Gulshan-e-lqbal KDA scheme

24, Karachi, Pakistan
}

(c) The Author(s). 2016 Open Access This article is distributed under the terms of the Creative Commons Attribution 4.0 International License (http://creativecommons.org/licenses/by/4.0/, which permits unrestricted use, distribution, and reproduction in any medium, provided you give appropriate credit to the original author(s) and the source, provide a link to the Creative Commons license, and indicate if changes were made. The Creative Commons Public Domain Dedication waiver (http://creativecommons.org/publicdomain/zero/1.0/) applies to the data made available in this article, unless otherwise stated. tion, and education, this will minimize donations from donors who might transmit diseases to the recipients. Equally important is to evaluate the burden and risk factors for TTIs in the general population [1]. The accurate figures of TTIs in our population are still unknown due to the lack of understanding, un-availability of screening tests, limited access to health facilities and the unavailability of surveillance systems [2]. Furthermore, voluntary donors have been reported to be the safest group of donors because they usually have better health seeking behavior than the replacement blood donors and 
their intention is to donate blood to an unknown patient out of compassion [3].

In Pakistan, more than 1.5 million units of blood are collected each year but the majority of these donors are replacement donors, mostly family members or close friends of the patient with the intention to help in most cases for transfusion under emergency situations [4]. There is an immense need to provide safe blood products. This requires high quality transfusion services and an organized infrastructure along with properly trained and well-educated staff [2].

The prevalence of Hepatitis B virus (HBV) and Hepatitis $\mathrm{C}$ virus $(\mathrm{HCV})$ in Pakistan is high and has been reported earlier (HBV: $2.5 \%$ and HCV: 4.9\%) [4]. However recent studies raised concerns regarding the increasing prevalence in trends of TTIs other than HBV and HCV, especially Human immunodeficiency viruses (HIV) and Syphilis $[2,3,5-8]$. The present study provides data on the overall seroprevalence of TTIs in blood donors and evaluates the demographic characteristics of seropositive donors.

\section{Methods}

This was a prospective cohort study of blood donors attending the National Institute of Blood disease and Bone Marrow transplantation (NIBD) donor's center from January 2013 to June 2015. Informed consent was taken from all donors. Blood donors were given a unique identification number and their name, age, sex, date of birth, profession, marital status and contact numbers were recorded. Before the donation, each potential donor was required to fill a detailed health history questionnaire which included data regarding their general health, life style, current or past febrile illness, weight loss, chronic disease, unusual or excessive bleeding, drug history, tattoo piercing, dental treatment, previous blood donation or transfusion, history of travel or immigration, sexual history and risk behaviors followed by short private interviews. Vitals and weight were also recorded. Baseline complete blood count $(\mathrm{CBC})$ was done for excluding any donors with anemia $(<12.5 \mathrm{~g} / \mathrm{dl})$, infection or thrombocytopenia. Moreover, inspection was made for any marks of drug abuse or any skin lesion at the veni puncture site. Proper sterilization and other precautions were taken during blood collection and blood units were stored using appropriate methods. Blood donors were then screened for HBV, HCV, HIV, Syphilis and Malaria.

\section{Laboratory tests}

Screening for HBsAg, Anti HCV, HIV Ag/Ab (HIV-1/ HIV-2) and Syphilis was done by chemiluminescent micro particle immunoassay (CMIA) method on Architect i2000 (Abbott Diagnostic, USA). Furthermore, Malaria was screened by thick films and through the immunochromatographic test (ICT) method. Reactive results were repeated on the same sample using the same method.

\section{Study subjects inclusion criteria}

Physically fit 18-55 year olds who donated blood at NIBD blood donor center were included.

\section{Study subjects exclusion criteria}

Potential donors were excluded if they were: below 18 years old, weigh $<50 \mathrm{~kg}$, anemic, had a history of jaundice, malaria, asthma, engaged in high risk behavior (i.e. unsafe intercourse, drug abuse), had past history of HBV, HCV, HIV I \& II or syphilis, or were apparently unhealthy or malnourished.

\section{Statistical analysis}

Data was analyzed using SPSS version 21. Infections among reactive and nonreactive blood donors were analyzed by using logistic regression and estimates of the odds ratio with their corresponding 95\% confidence interval. Chi Square was applied to find the association of co-infections with demographic variables. $P$-value $<0.05$ was considered significant in all analysis.

\section{Results}

A total of 16,602 donors who visited for blood donation were screened; 16,557 were males and 45 females, with a mean age of $28.6 \pm 2$ years (range 18 to 55 years), of which $95 \%$ were replacement blood donors. Of all donations, $973(5.8 \%)$ were reactive in the screening assays, among them $58(0.35 \%)$ were reactive in more than one assay. The prevalence of HCV, HBV, HIV, syphilis and malaria in our study population was 1.8, 1.7, 0.04, 2.1 and $0.07 \%$ respectively. The overall demographic variables among the reactive and non-reactive donors are shown in (Table 1). Characteristics among infections were individually evaluated, as shown in (Table 2). It was found that unmarried donors were more likely to be positive for HBV infection (OR-CI: 0.331:0.202-0.570, $P$-value: 0.001 ) and Syphilis (OR-CI: 0.182:0.065-0.512, $P$-value: 0.001$)$ rather than the other infections. The construction workers (OR-CI: 0.219:0.129-0.370, $P$-value: 0.000 ) and married persons (OR-CI: 0.360:0.158-0.820, $P$-value: 0.015$)$ have a higher chance to be positive for Syphilis than the other infections. The association of gender, age groups, education, number of donations, and residential status was not significant for any of the studied infections. We observed the trend of co-infections (risk to be infected by more than one pathogens) in the sub categories of our donors and it was found that the subcategory of occupation $(P$-value $=0.01)$ and the subcategory of marital status $(P$-value $=0.00)$ were significant. (Table 3) 
Table 1 Demographic variables of reactive and non-reactive blood donors

\begin{tabular}{|c|c|c|}
\hline \multicolumn{3}{|l|}{ Characteristics } \\
\hline & Non-React. & React. \\
\hline \multicolumn{3}{|l|}{ Age groups } \\
\hline $18-25$ & 8010 & 466 \\
\hline $26-35$ & 6110 & 402 \\
\hline More than 35 & 1509 & 105 \\
\hline \multicolumn{3}{|l|}{ Gender } \\
\hline Female & 42 & 3 \\
\hline Male & 15587 & 970 \\
\hline \multicolumn{3}{|l|}{ Occupation } \\
\hline Student & 1471 & 110 \\
\hline Businessman & 4000 & 173 \\
\hline Driver & 3790 & 269 \\
\hline Employee & 2789 & 197 \\
\hline Construction worker/laborer & 4190 & 224 \\
\hline \multicolumn{3}{|l|}{ Education } \\
\hline Illiterate & 6420 & 180 \\
\hline Literate & 9209 & 793 \\
\hline \multicolumn{3}{|l|}{ Number of donations } \\
\hline Repeat donation & 4774 & 128 \\
\hline First donation & 10855 & 845 \\
\hline \multicolumn{3}{|l|}{ Marital status } \\
\hline Divorced & 1268 & 742 \\
\hline Unmarried & 8864 & 143 \\
\hline Married & 5497 & 88 \\
\hline \multicolumn{3}{|l|}{ Resident } \\
\hline Rural & 5863 & 110 \\
\hline Urban & 9766 & 863 \\
\hline
\end{tabular}

\section{Discussion}

Blood transfusion is a life-saving procedure of modern medicine. Stringent screening of blood not only gives us an idea about the prevalence of TTIs in healthy populations but also ensures the safe supply of blood and blood products. [9]. Disease burden estimations based on sound epidemiological research form the basis of public policy. Similarly, the exact evaluations of the risk of TTIs is imperative in order to monitor the safety of blood supply and gauging the effectiveness of the presently employed screening procedures, as discussed by Busch et al. [10]. According to one study, in Pakistan the majority of the blood donors are first timers, which can be considered a true reflection of infection amongst the community [9]. However, according to other studies, blood donors may not represent the general population as the prevalence rate may be underestimated or overestimated due to their different characteristics [11, 12].
Since most of them are male, young or middle-aged, the source of prevalence may underestimate the actual prevalence. This view seems more valid as opposed to the previous one simply because females comprise more than 50\% of Pakistan's population. The prevalence of TTIs among blood donors in a well-structured health care system coupled with a well-organized blood establishment can be used as a reliable tool for statistical calculation of those infectious agents that can be transmitted through blood products in the populations, as discussed by Gharehbaghian and Chandra et al. [1, 13].

In our study, most of the donors were replacement blood donors i.e. 95\% which is comparable with other local studies in which majority of blood donations were contributed by replacement donors [4, 14] with the intention to help a friend, relative or acquaintance who needed blood transfusion. The maximum number of donors came from the 18-30 year age group. A similar trend was seen in earlier reports $[15,16]$. Furthermore, efforts should also be made to encourage and improve the number of female donors, as our study shows limited number of female donors. In this study, a significant increase in the seroprevalence of syphilis was observed among blood donors over the study period, which was found to be $2.1 \%$. A local study that was done previously had also observed a rising seroprevalence of $0.89 \%$ [17]. This finding is consistent with the increasing trend of syphilis seropositivity observed in blood donors of Israel [18]. A study done in Iran also found a rising trend of syphilis frequency in their population; however, the frequency found in this study was $0.04 \%$ [19]. Previous local data shows low seroprevalence from 0.22 to $0.89 \%$, which is contrary to that observed in our study [4, 20-22]. Another study found a downward trend in seroprevalence [3]. Moreover, Moiz et al. observed similar results in their study [23]. Furthermore, studies done in India had very low prevalence as compared to our study [15, 24]. Thus, the seroprevalence of syphilis in blood donors observed in our study was high as compared to the previous local and international data. Since citizens perform blood donation(s), it could provide an updated picture about prevalence of Syphilis in the Pakistani population.

However, one of the limitations in our study is that positivity of Syphilis could not be further validated by confirmatory assay and positivity could only give indication as a surrogate marker.

There is also limited surveillance data for HIV in Pakistan. Current study reports the figure of $0.04 \%$, which is slightly higher than the one reported in studies by Attaullah, Manzoor and Sultan et al. [2, 4, 21]. HIV positive blood units were confirmed with other techniques in the reference HIV laboratory.

Acute and chronic viral hepatitis are the most reported health problems in Pakistan and usually bring with them 
Table 2 Demographic variables of individual Infections among reactive and non-reactive blood donors

\begin{tabular}{|c|c|c|c|c|c|c|c|c|c|c|c|c|}
\hline \multirow[t]{2}{*}{ Characteristics } & \multicolumn{3}{|c|}{$\mathrm{HBsAg}(n=290)$} & \multicolumn{3}{|c|}{ Anti HCV $(n=307)$} & \multicolumn{3}{|l|}{$\mathrm{MP}(n=12)$} & \multicolumn{3}{|c|}{ Syphilis $(n=357)$} \\
\hline & Non react. & React & $P$-value & Non Ract. & React & $P$-value & Not seen & Seen & $P$-value & Non react. & React & $P$-value \\
\hline \multicolumn{13}{|l|}{ Age groups } \\
\hline $18-25$ & 8314 & 156 & 0.847 & 8340 & 131 & 0.616 & 8468 & 7 & 0.987 & 8291 & 170 & 0.177 \\
\hline $26-35$ & 6394 & 111 & 0.745 & 6364 & 144 & 0.063 & 6501 & 5 & 0.988 & 6357 & 154 & 0.357 \\
\hline More than $35^{*}$ & 1604 & 23 & & 1591 & 32 & & 1629 & 0 & & 1597 & 33 & 0.861 \\
\hline \multicolumn{13}{|l|}{ Gender } \\
\hline Female & 45 & 0 & 0.998 & 44 & 1 & 0.504 & 45 & 0 & 0.998 & 45 & 0 & 0.998 \\
\hline Male* & 16267 & 290 & & 16251 & 306 & & 16541 & 12 & & 16186 & 357 & \\
\hline \multicolumn{13}{|l|}{ Occupation } \\
\hline Student* & 1508 & 54 & & 2496 & 54 & & 1770 & 0 & & 2077 & 36 & \\
\hline Businessman & 4076 & 77 & 0.924 & 3796 & 77 & 0.986 & 3182 & 5 & 0.999 & 3727 & 28 & 0.220 \\
\hline Driver & 3776 & 52 & 0.977 & 3596 & 61 & 0.997 & 4753 & 3 & 0.997 & 3486 & 50 & 0.593 \\
\hline Office Employee & 2776 & 32 & 0.982 & 2848 & 41 & 0.996 & 3640 & 0 & 0.97 & 3736 & 22 & 0.989 \\
\hline Construction worker/laborer & 4176 & 75 & 0.977 & 3559 & 74 & 0.997 & 3245 & 4 & 0.995 & 3219 & 221 & 0.000 \\
\hline \multicolumn{13}{|l|}{ Education } \\
\hline Illiterate ${ }^{*}$ & 6408 & 169 & 0.975 & 5242 & 178 & 0.972 & 6185 & 6 & 0.095 & 5192 & 233 & 0.686 \\
\hline Literate & 9904 & 121 & & 11053 & 129 & & 10405 & 6 & & 11053 & 124 & \\
\hline \multicolumn{13}{|l|}{ Number of donations } \\
\hline Repeat donation* & 4783 & 106 & 0.986 & 4506 & 134 & 0.984 & 6203 & 2 & 0.936 & 4419 & 128 & 0.053 \\
\hline First donation & 11529 & 184 & & 11789 & 173 & & 10387 & 10 & & 11826 & 229 & \\
\hline \multicolumn{13}{|l|}{ Marital status } \\
\hline Divorced* & 2259 & 74 & & 1480 & 81 & & 4873 & 1 & & 1513 & 13 & \\
\hline Unmarried & 8327 & 136 & 0.00 & 7765 & 146 & 0.985 & 7911 & 5 & 0.959 & 7837 & 83 & 0.001 \\
\hline Married & 5726 & 80 & 0.987 & 7050 & 80 & 0.979 & 3806 & 6 & 0.938 & 6895 & 261 & 0.015 \\
\hline \multicolumn{13}{|l|}{ Residential status } \\
\hline Rural & 5852 & 103 & 0.994 & 7748 & 158 & 0.999 & 6802 & 6 & 0.948 & 7670 & 267 & 0.826 \\
\hline Urban* & 10460 & 187 & & 8547 & 149 & & 9788 & 6 & & 8575 & 90 & \\
\hline
\end{tabular}

*reference category

serious complications. Local data regarding the prevalence of HBV and HCV infections among healthy blood donors is well recognized [12, 14, 17, 25] except by the Mahmood et al. study [26], which shows less percentage of HBsAg and anti HCV.

Risk behavior-based donor selection is the cornerstone of the availability of safe blood. It is dependent on donor education as well as the accurate and truthful disclosure of risk behavior [12]. In our study, risk factors were assessed using a questionnaire but many blood donors were reluctant to disclose any risk behavior(s) because of the potential fear of judgment, embarrassment, test-seeking behavior, or due the genuine belief that their blood was safe [12]. We have over all observed risk factors among the blood donors in our study however they were not analyzed for each blood donor's category individually. Therefore, we could only simulate risk factors among blood donors based on local studies on HBV and HCV infections [11, 12].
The focus of our study was also to determine the demographic characteristics of reactive blood donors. Positive donors for any infection were informed and requested to visit general physicians. A short interview was conducted to find more details regarding the life styles of reactive blood donors. This is the first local study in our region, which shows detailed demographic characteristics information regarding blood donors.

\section{Conclusion}

A substantial percentage of the blood donor's harbored transfusion transmitted infections. Prevention of TTIs should be the main goal right now. There is a need for stringent selection of blood donors with the emphasis on getting voluntary donations and comprehensive screening of donor's blood for HCV, HBV, HIV, Syphilis and Malaria using standard methods to safeguard the blood recipient. By assessing the rising trend of Syphilis 
Table 3 Association of Co-infections with demographic variables

\begin{tabular}{|c|c|c|c|}
\hline \multirow[t]{2}{*}{ Characteristics } & \multicolumn{3}{|c|}{ Co-Infections $(N=58)$} \\
\hline & Non reactive & Reactive & $P$-value \\
\hline \multicolumn{4}{|l|}{ Age groups } \\
\hline $18-25$ & 8446 & $30(0.35 \%)$ & \multirow[t]{3}{*}{0.791} \\
\hline $26-35$ & 6491 & $21(0.32 \%)$ & \\
\hline More than 35 & 1607 & $7(0.43 \%)$ & \\
\hline \multicolumn{4}{|l|}{ Gender } \\
\hline Female & 45 & 0 & \multirow[t]{2}{*}{0.691} \\
\hline Male & 16,499 & $58(0.35 \%)$ & \\
\hline \multicolumn{4}{|l|}{ Occupation } \\
\hline Student & 1433 & $4(0.27 \%)$ & \multirow[t]{5}{*}{0.01} \\
\hline Businessman & 4080 & $6(0.14 \%)$ & \\
\hline Driver & 3755 & $23(0.61 \%)$ & \\
\hline Office employee & 2735 & $12(0.43 \%)$ & \\
\hline Construction worker/laborer & 4177 & $13(0.31 \%)$ & \\
\hline \multicolumn{4}{|l|}{ Education } \\
\hline Illiterate & 6597 & $29(0.43 \%)$ & \multirow[t]{2}{*}{0.11} \\
\hline Literate & 9947 & $29(0.29 \%)$ & \\
\hline \multicolumn{4}{|l|}{ Number of donations } \\
\hline Repeat donation & 4899 & $17(0.34 \%)$ & \multirow[t]{2}{*}{0.95} \\
\hline First donation & 11,624 & $41(0.35 \%)$ & \\
\hline \multicolumn{4}{|l|}{ Marital status } \\
\hline Divorced & 1954 & $19(0.97 \%)$ & \multirow[t]{3}{*}{0.00} \\
\hline Unmarried & 8141 & $22(0.27 \%)$ & \\
\hline Married & 5585 & $17(0.30 \%)$ & \\
\hline \multicolumn{4}{|l|}{ Residential status } \\
\hline Rural & 5974 & $28(0.46 \%)$ & \multirow[t]{2}{*}{0.54} \\
\hline Urban & 10,570 & $30(0.28 \%)$ & \\
\hline
\end{tabular}

in Pakistan, special attention should be given to targeted blood donor's population and the population at risk. A future study is also planned to assess the knowledge, attitude and behavior of the blood donor's population. These measures will improve public health and would increase blood safety and quality.

\section{Abbreviations}

CBC: Complete blood count; CMIA: Chemiluminescent micro particle immunoassay; HBV: Hepatitis B virus; HCV: Hepatitis C virus; HIV: human immunodeficiency virus; ICT: Immunochromatographic test; TTIs: Transfusion-transmitted infections; WHO: World Health Organization

\section{Acknowledgements}

The authors would also like to acknowledge the donor's area for their support in conducting interviews and the ethics committee for their approval to conduct this study.

\section{Funding}

No funding.

\section{Availability of data and material}

The datasets generated during and/or analyzed during the current study are not publicly available due to hospital ethical policy in order to protect participant confidentiality.

\section{Authors' contributions}

AA contributed in literature search and manuscript writing. MB and $\mathrm{NI}$ had the main idea of the study and contributed in manuscript writing, IN, RA and SB contributed in blood banking work. NF and MZ contributed in statistical analysis. TS supervised the study \& critically reviewed the manuscript All authors read and approved the final manuscript.

\section{Competing interests}

The authors declare that they have no competing interests.

\section{Consent for publication}

Not Applicable.

\section{Ethics approval and consent to participate}

Written informed consent was taken from all donors. This study was approved by the hospital ethics committee (NIBD Ethics Committee)

Received: 1 September 2016 Accepted: 9 November 2016

Published online: 18 November 2016

References

1. Ahmad G. An estimate of transfusion-transmitted infection prevalence in general populations. Hepat Mon. 2011;11(12, Dec):1002-3.

2. Attaullah $\mathrm{S}$, Khan $\mathrm{S}$, Khan J. Trend of transfusion transmitted infections frequency in blood donors: provide a road map for its prevention and control. J Transf Med. 2012;10(1):1.

3. Motayo BO, Faneye AO, Udo UA, Olusola BA, Ezeani I, Ogiogwa J. Seroprevalence of transfusion transmissible infections (TTI), in first time blood donors in Abeokuta, Nigeria. Afr Health Sci. 2015;15(1):19-24.

4. Manzoor I, Hashmi NO, Daud SE, Ajmal SA, Fatima HI, Rasheed ZA, Syed SA. Seroprevalence of transfusion transmissible infections (TTIS) in blood donors. Biomedica. 2009;25(10):154-8.

5. Mogtomo ML, Fomekong SL, Kuate HF, Ngane AN. Screening of infectious microorganisms in blood banks in Douala (1995-2004). Sante (Montrouge, France). 2008;19(1):3-8.

6. Zou S, Notari EP, Fang CT, Stramer SL, Dodd RY. Current value of serologic test for syphilis as a surrogate marker for blood-borne viral infections among blood donors in the United States. Transfusion. 2009:49(4):655-61.

7. Liu J, Huang Y, Wang J, Guo N, Li J, Dong X, Ma H, Tiemuer M, Huang M, Wright DJ, Ness $P$. The increasing prevalence of serologic markers for syphilis among Chinese blood donors in 2008 through 2010 during a syphilis epidemic. Transfusion. 2012;52(8):1741-9.

8. Ji ZH, Li CY, Lv YG, Cao W, Chen YZ, Chen XP, Tian M, Li JH, An QX, Shao ZJ. The prevalence and trends of transfusion-transmissible infectious pathogens among first-time, voluntary blood donors in Xi'an, China between 1999 and 2009. Int J Infect Dis. 2013;17(4):e259-62.

9. Khan ZT, Asim S, Tariq Z, Ehsan MA, Malik RA, Ashfaq B, Hayat A. Prevalence of transfusion transmitted infectious in healthy blood donors in Rawalpindi District, Pakistan: a five-year survey. Int J Pathol. 2007:5(1):21-5.

10. Busch MP, Glynn SA, Stramer SL, Strong DM, Caglioti S, Wright DJ, Pappalardo B, Kleinman SH. A new strategy for estimating risks of transfusion-transmitted viral infections based on rates of detection of recently infected donors. Transfusion. 2005:45(2):254-64.

11. Jafri W, Jafri N, Yakoob J, Islam M, Tirmizi SF, Jafar T, Akhtar S, Hamid S, Shah HA, Nizami SQ. Hepatitis B and C: prevalence and risk factors associated with seropositivity among children in Karachi, Pakistan. BMC Inf Dis. 2006:6(1):1.

12. Ali SA, Donahue RM, Qureshi H, Vermund SH. Hepatitis B and hepatitis C in Pakistan: prevalence and risk factors. Int J Infect Dis. 2009;13(1):9-19.

13. Chandra T, Rizvi S, Agarwal D. Decreasing prevalence of transfusion transmitted infection in Indian scenario. Sci World J. 2014;27:2014.

14. Zaheer $H$, Saeed U, Waheed Y, Karimi S, Waheed U. Prevalence and trends of hepatitis $B$, hepatitis $C$ and human immunodeficiency viruses among blood donors in Islamabad, Pakistan 2005-2013. J Blood Disord Transf. 2014;5(217):2. 
15. Rao P, Annapurna K. KHIV status of blood donors and patients admitted in KEM hospital Pune. Ind Hematol Blood Transf. 1994;12:174-6.

16. Rose D, Sudarsanam A, Pandankatti T, Babu PG, John TJ. Increasing prevalance of HIV antibody among blood donors monitored over 9 years in one blood bank. Ind J Med Res. 1998;108:42.

17. Waheed U, Khan H, Satti HS, Ansari MA, Malik MA, Zaheer HA. Prevalence of transfusion transmitted infections among blood donors of a teaching hospital in Islamabad. Ann Pak Inst Med Sci. 2012;8(4):236-9.

18. Kerzman H, Green MS, Shinar E. Risk factors for hepatitis C virus infection among blood donors in Israel: a case-control study between native Israelis and immigrants from the former Soviet Union. Transfusion. 2007;47(7):1189-96.

19. Hosseien K, Seyyed Mohammad M, Mohsen A, Hassan A, Bashir H, Farshid A, Farahnaz F. Trends in seroprevalence of hepatitis B, hepatitis C, HIV, and syphilis infections in Iranian blood donors from 2003 to 2005. Hepat Mon. 2009;2009(1, Winter):24-8.

20. Khan EA, Khokhar NA, Malik GJ. Seroprevalence of syphilis in asymptomatic adults seeking employment abroad. Rawal Med J. 2004;29(2):65-7.

21. Sultan F, Mehmood T, Mahmood MT. Infectious pathogens in volunteer and replacement blood donors in Pakistan: a ten-year experience. Int J Infect Dis. 2007;11(5):407-12.

22. Zaheer HA, Waheed U. National baseline survey on monitoring and evaluation of blood screening systems in Pakistan. J Blood Disord Transf. 2015;7:2015

23. Moiz B, Naseem AS, Khurshid M. Seroprevalence of syphilis in healthy non commercial blood donors in Karachi. J Coll Physicians Surg Pak. 2006;16(5):385-6.

24. Bhawani Y, Rao PR, Sudhakar V. Seroprevalence of transfusion transmissible infections among blood donors in a tertiary care hospital of Andhra Pradesh. Biol Med. 2010;2(4):45-8.

25. Hasan K. Study of hepatitis B and C virus seropositivity in healthy blood donors. Ann Pak Inst Med Sci. 2009;5(4):233-6.

26. Mahmood MA, Khawar S, Anjum AH, Ahmed SM, Rafig S, Nazir I, Usman M. Prevalence of hepatitis B, C and HIV infection in blood donors of Multan region. Ann King Edward Med Coll. 2004;10:459-61.

\section{Submit your next manuscript to BioMed Central and we will help you at every step:}

- We accept pre-submission inquiries

- Our selector tool helps you to find the most relevant journal

- We provide round the clock customer support

- Convenient online submission

- Thorough peer review

- Inclusion in PubMed and all major indexing services

- Maximum visibility for your research

Submit your manuscript at www.biomedcentral.com/submit 